\title{
Consejos básicos para sobrevivir a la elaboración de un Plan de Protección de Colecciones ante Emergencias: la experiencia práctica del Museo Nacional del Prado
}

\author{
Estrella Sanz Domínguez, Marta Hernández Azcutia
}

\begin{abstract}
Resumen: Este artículo tiene como objetivo exponer, desde la perspectiva de una experiencia práctica, la metodología utilizada para la redacción del Plan de Protección de Colecciones ante Emergencias del Museo Nacional del Prado, ofreciendo a técnicos dedicados a la conservación de patrimonio cultural e implicados en la elaboración de planes similares, consejos básicos para salvar escollos recurrentes que pueden obstaculizar su llegada a buen puerto. El contenido se organiza en diez apartados relativos a: conservación preventiva, seguridad y plan de autoprotección, planimetrías, análisis de espacios y recursos, jerarquización de colecciones, protección in situ, rutas de evacuación, equipos internos de intervención, coordinación con agentes externos y, finalmente, evaluación del siniestro. En cada punto se analizan los aspectos clave, se define su desarrollo ideal y se formula una propuesta de tareas mínimas indispensables con la finalidad de dar un uso eficiente a los recursos disponibles.
\end{abstract}

Palabras clave: conservación preventiva, emergencias, plan de protección de colecciones, jerarquización de colecciones, protección in situ

\section{Conselhos básicos para sobreviver à elaboração de um Plano de Proteção de Coleções para Emergências: a experiência prática do Museu Nacional do Prado}

Resumo: Este artigo tem como objetivo expor, na perspetiva de uma experiência prática, a metodologia utilizada para a redação do Plano de Proteção de Acervos em Emergências do Museu Nacional do Prado, oferecendo a técnicos dedicados à conservação do património cultural e a envolvidos no desenvolvimento de planos semelhantes, conselhos básicos para evitar obstáculos recorrentes que podem impedir a sua chegada a bom porto. O conteúdo está organizado em dez seções relativas a: conservação preventiva, plano de segurança e autoproteção, planimetrias, análise de espaços e recursos, hierarquia de coleções, proteção in situ, rotas de evacuação, equipas de intervenção interna, coordenação com agentes externos e, por último, avaliação do sinistro. Em cada ponto, são analisados os aspetos-chave, define-se o seu desenvolvimento ideal e formula-se uma proposta de tarefas mínimas essenciais para a utilização eficiente dos recursos disponíveis.

Palavras-chave: conservação preventiva, emergências, plano de proteção de coleção, hierarquia de coleção, proteção in situ

\section{Basic advice for surviving the preparation of an Emergency Collection Protection Plan: the practical experience of the Museo Nacional del Prado}

\footnotetext{
Abstract: The aim of this paper is to present, the methodology used to draw up the Emergency Collection Protection Plan of the Museo Nacional del Prado, based on practical experience. It offers technicians dedicated to the conservation of cultural heritage and involved in the preparation of similar plans basic advice on how to overcome recurring obstacles that may hinder their successful completion. The content is organised into ten sections relating to: preventive conservation, security and self-protection plan, planimetries, analysis of spaces and resources, collection hierarchy, in situ protection, evacuation routes, internal intervention teams, coordination with external agents and, finally, assessment of the incident. At each point, the key aspects are analysed, their ideal development is defined and a proposal of minimum essential tasks is formulated in order to make efficient use of the available resources.
}

Keyword: preventive conservation, emergencies, collection protection plan, collection hierarchy, in situ protection 


\section{Introducción}

Dos pavorosos incendios: el del Museo Nacional de Río (Brasil) en 2018 y el de la catedral de Notre Dame (París, Francia) en 2019 provocaron una respuesta general en instituciones culturales con la adopción de medidas preventivas que se acogen al marco normativo de Sendai para la reducción del riesgo de desastres (UNDRR United Nations Office for Disaster Risk Reduction, 2015) y que, en el caso de museos, consisten en la elaboración de los denominados comúnmente "Planes de Salvaguarda".

El desencadenamiento de la pandemia provocada por el virus COVID-19, ha llevado a los museos a una reflexión profunda sobre la categorización de los riesgos y su impacto tanto directo como secundario. La incertidumbre actual derivada de la crisis sanitaria, si bien no permite valorar con exactitud el alcance de los posibles daños sobre el sector cultural en general, nos impulsa a trabajar en el terreno de la prevención de riesgos sobre nuestras colecciones, como opción segura para garantizar la resiliencia.

La obligación de reducir el riesgo y las pérdidas de bienes culturales recae principalmente en los Estados, pero debe compartirse con los actores locales para alcanzar con eficacia su objetivo. Los técnicos de museos y los gestores de patrimonio son los agentes clave para redactar los planes e implantar las medidas de protección.

El beneficio social indirecto de la redacción de estos planes aplicados al patrimonio cultural, aunque difícil de cuantificar, justifica de sobra el esfuerzo realizado, independientemente de que se dirijan tanto a bienes culturales de interés local en entornos muy aislados como a grandes museos de relevancia internacional.

Los consejos presentados en este artículo derivan de la experiencia práctica, aplicada en el Museo Nacional del Prado, que ha permitido a las autoras identificar los aspectos ineludibles del tema tratado y organizarlos en forma de documentos, criterios, principios de actuación o procedimientos operativos. Constituyen una herramienta de referencia sencilla para saber por dónde empezar con la ingente tarea de proteger los bienes culturales custodiados por cada institución ante situaciones de emergencia y una fuente de información actualizada a la que recurrir. Estos son los diez puntos en que se agrupan los contenidos básicos:

-Conservación Preventiva

-Seguridad y Plan de Autoprotección

-Planimetrías

-Análisis de espacios y recursos

-Jerarquización de colecciones

-Protección in situ

-Rutas de evacuación

-Equipos internos de intervención

-Coordinación con agentes externos

-Evaluación del siniestro
Esta reducida relación de cuestiones clave sirve de guía para reflexionar sobre el estado de la cuestión en cada museo (fortalezas y carencias) y decidir en qué línea de trabajo queremos o debemos profundizar, sin necesidad de seguir estrictamente la secuencia sugerida y permitiendo una adaptación a los variables recursos disponibles.

\section{Conservación Preventiva}

La clave. La implantación de una política de conservación preventiva eficaz garantiza la pervivencia de los bienes culturales en situaciones cotidianas. De su desarrollo práctico depende íntimamente la reducción del riesgo tanto en circunstancias ordinarias como durante emergencias.

Lo ideal. Redactar un Plan de Conservación Preventiva completo que implique a todo el personal de la institución incidiendo en aspectos fundamentales como la gestión de uso de la colección, las condiciones climáticas, la calidad del aire, la manipulación de obras, el control de plagas, la limpieza y mantenimiento de instalaciones, la iluminación y la seguridad en salas y zonas de reserva. Implica el análisis de las colecciones, el entorno, los espacios y su equipamiento técnico.

Los principios de conservación preventiva deben aplicarse en todos los proyectos museísticos pequeños o grandes, aprovechando la existencia de presupuesto para costear pequeñas mejoras ( $p$. ej. eliminar materiales con COVs dañinos de una vitrina reutilizada) o, yendo a máximos, para implantar criterios estructurales en proyectos arquitectónicos de nueva planta. Todo esfuerzo invertido en mejorar las condiciones cotidianas de conservación preventiva de nuestras colecciones redundará automáticamente en la desaparición de agentes de riesgo presentes en los espacios con bienes culturales o en la minimización de los posibles daños que podrían causar.

Podemos afirmar que la redacción de un Plan de Protección de Colecciones ante Emergencias supone una extensión de las políticas de conservación preventiva de una institución, llevándolas al límite y enfocándolas hacia situaciones extremas. La lógica profesional nos llevará a entender que si carecemos de una sólida implantación de los principios básicos de conservación preventiva en nuestras colecciones deberemos incidir en su mejora antes de pretender pasar directamente a la gestión de situaciones de emergencia. En cualquier caso, son dos tareas de planificación que se retroalimentan generando beneficios mutuos.

Al igual que cualquier Plan de Salvaguarda, el Plan de Conservación Preventiva requiere de una revisión y actualización periódicas [figuras 1, 2]. En ambos casos, 

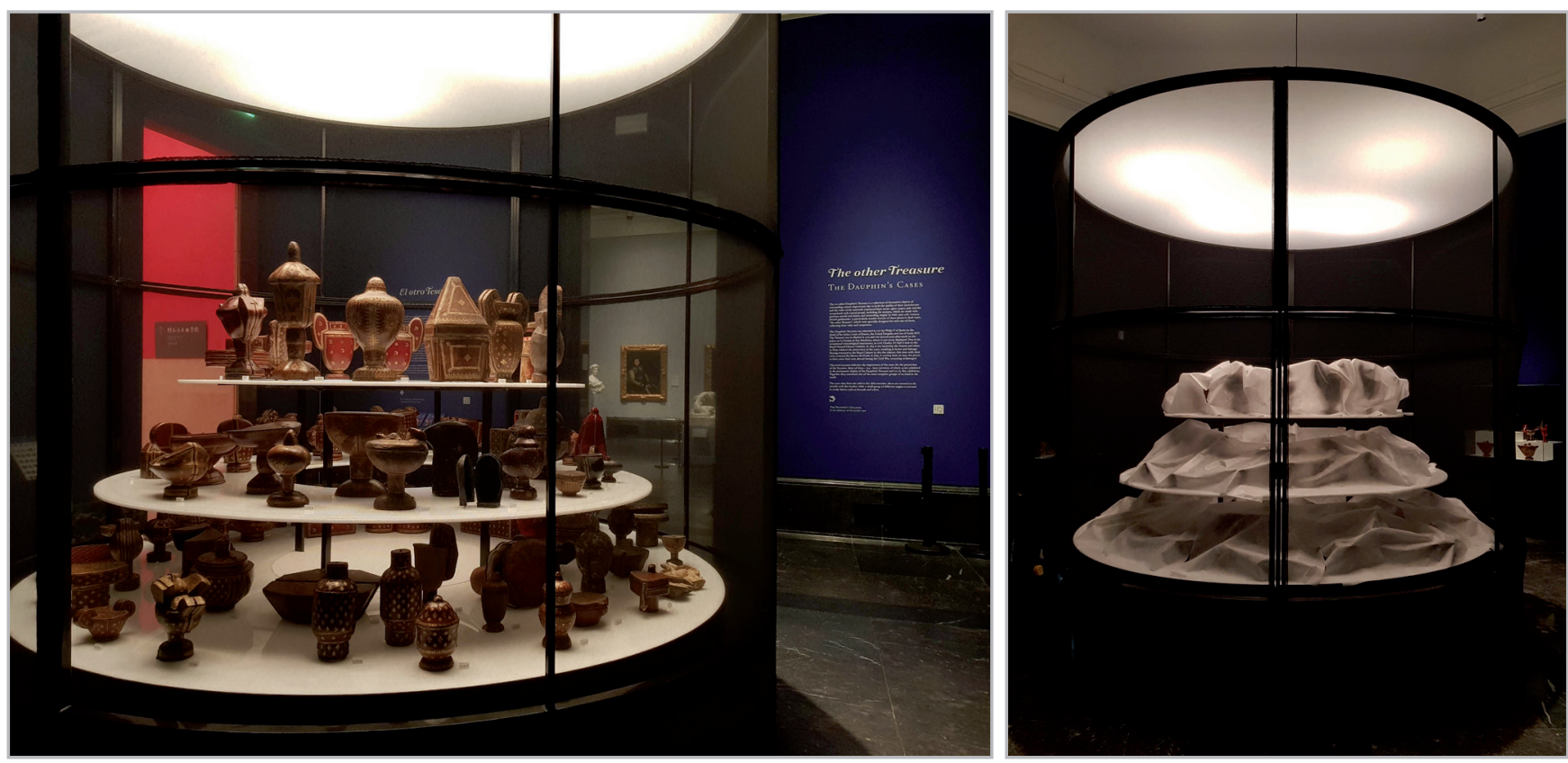

Figura 1 y 2.- Vista de El otro Tesoro. Los estuches del Delfín, montaje temporal abierto al público y montaje temporal cerrado por COVID-19. Fotos: Marta Hernández.

es esencial comunicar y compartir los procedimientos, recursos y criterios con todo el personal de la institución.

Lo indispensable. Entender y corregir los riesgos cotidianos con la finalidad de implantar mejoras que redunden en la conservación de los bienes.

\section{Seguridad y Plan de Autoprotección}

La clave. El Plan de Autoprotección es el documento que vertebra la seguridad de las personas y del inmueble. Refleja los riesgos presentes en el museo y obliga a reflexionar sobre aspectos no mencionados que puedan afectar a los bienes culturales. Es, por tanto, la referencia a seguir y el contexto del que "descuelga" el Plan de Protección de Colecciones.

Lo ideal. Contar con un departamento específico, con personal cualificado que asuma como responsabilidad la seguridad del inmueble, de sus empleados y visitantes $y$, primordialmente, de sus colecciones, de modo que sus trabajadores actúen como "efectivos de choque" en la detección de amenazas y cuenten con instrumentos para neutralizarlas, esto es: sistemas de detección de intrusión, detección y extinción de incendios, manuales de intervención en emergencias, etc.

Según los distintos modelos organizativos, cada institución contará con dotación más o menos numerosa de personal de seguridad y vigilancia para poner en práctica los procedimientos operativos críticos para la seguridad de visitantes y personal, por ejemplo, el desalojo ordenado del edificio. Si, además, existe un departamento dedicado al control y prevención de riesgos laborales, su intervención será crucial.
Los empleados están obligados a asumir las tareas que el Plan de Autoprotección les imponga y a la realización de simulacros periódicos para mantener el conocimiento actualizado. Al ser compartido por todo el personal, queda abonado el terreno para la redacción e implantación de un plan específico para colecciones.

Al trabajar en la redacción de este último, analizando previamente el contenido de nuestro Plan de Autoprotección, se produce una retroalimentación que permite la detección de carencias cuya corrección acabará repercutiendo positivamente en la propia seguridad de las personas y viceversa. Es esencial que el contenido de ambos planes se interrelacione fluidamente y $\sin$ incongruencias.

En el Plan de Autoprotección, como mínimo, debe identificarse al Coordinador para situaciones de emergencias que afecten a colecciones y a los miembros de los distintos equipos. También es esencial marcar sobre plano las ubicaciones de los materiales de protección, bien se trate de carros, armarios o almacenes.

Es muy aconsejable categorizar en el Plan de Autoprotección como "locales de riesgo especial" los almacenes de bienes culturales significativamente valiosos y conservar en el mismo lugar, bien identificados, los dos planes.

Lo indispensable. Conocer los aspectos básicos de nuestro Plan de Autoprotección actualizado y utilizarlos como base para la redacción del "Plan de Protección de Colecciones ante Emergencias". Son especialmente importantes los riesgos presentes, la sectorización de espacios y la organización de equipos. 


\section{Planimetrías}

La clave. Las planimetrías permiten tener un conocimiento general del edificio y su entorno, aportan información sobre su ubicación, características constructivas, uso, distribución de espacios y accesos. Son fuente de información y un medio de representación visual clara, sencilla y sintetizada fundamental en el Plan de Protección de Colecciones ante Emergencias.

Lo ideal. Lo ideal es disponer de planos completos y actualizados de mayor a menor escala que nos aporten la información necesaria para abordar nuestro plan de protección, pero también que nos permitan incorporar con claridad datos acordes al asunto tratado o propósito dentro del plan. El conjunto de planimetrías necesarias constaría de:

- Plano de situación: plano, a la escala adecuada, de la zona donde se localiza el edificio y en el que se muestra su entorno. En él, además de marcar el emplazamiento del edificio, podemos localizar otras infraestructuras útiles y necesarias para nuestro propósito, como pueden ser parques de bomberos próximos.

- Plano de emplazamiento: este plano supone una vista aumentada del plano de situación en el que queda delimitada la parcela del edificio, identificándose calles próximas e incluso edificaciones cercanas. En él ubicamos accesos, zonas del pavimento sin suficiente capacidad de carga para el estacionamiento o tránsito de vehículos pesados de emergencias, localización de hidrantes próximos o zonas de triaje y rutas en caso de evacuación externa.

- Planos de planta y alzado acotados: estos planos van a tener un carácter informativo al reflejar datos sobre medidas de superficie necesarias para proponer, por ejemplo, posibles zonas de almacenamiento temporal, o dimensiones de vanos que ayuden a confirmar la viabilidad de rutas de evacuación según formatos de las obras.

- Planos de instalaciones: al igual que los anteriores también de índole informativa, pero muy interesantes dado que nos van a ayudar a localizar y analizar posibles zonas de riesgo relacionadas con agua o plagas; o a entender, por ejemplo, cómo habría que actuar para la ventilación y evacuación de humos tras un incendio. Nos referimos a planos de instalaciones de fontanería, sistema de climatización e instalación eléctrica. Por otro lado, del Plan de Autoprotección podemos obtener los planos en los que se reflejan los sistemas de protección (detección y extinción de incendios y sistema de seguridad).

- Planos de planta de espacios: donde incorporar la distribución de las obras expuestas identificadas con su número de inventario o identificar los contenedores para su almacenamiento. Las obras prioritarias de evacuación se deben señalar en este plano.
- Planos con rutas de evacuación: en estos planos, que incorporaremos a nuestro documento de salvaguarda, trazamos la ruta -o posibles rutas de evacuación si creemos necesario aportar varías alternativas-, desde el espacio afectado a la zona de triaje y posterior destino de almacenamiento temporal si es una evacuación interna o, en caso contrario, hacia la zona de salida y triaje exterior si hablamos de evacuación externa.

Lo indispensable. Consideramos como indispensable disponer o elaborar planos de planta en los que poder incorporar, al menos, la ubicación de las obras prioritarias de evacuación o protección in situ y las rutas de evacuación interna o rutas hasta la zona de triaje externa si la primera opción no es posible.

\section{Análisis de espacios y recursos}

La clave. Con el análisis de espacios y recursos perseguimos tener una percepción clara y global, no sólo de cuál es el uso del espacio, cómo son las instalaciones, o cuáles son los servicios o dotaciones de los que se dispone sino, además, si la concurrencia de todas estas cuestiones puede suponer un riesgo, de qué nivel, si los recursos identificados son suficientes y si se adecuan a la labor de conservación y protección ante emergencias de las colecciones (Dorge y Jones 2004: 115).

Lo ideal. Lo deseable para comenzar con el análisis de los diferentes espacios y recursos, es disponer de parte las planimetrías antes mencionadas y de información de primera mano de los encargados del control de los posibles riesgos. Comúnmente estos riesgos están relacionados con terrorismo, robo, vandalismo, daño por fuerzas físicas, fuego, agua, interrupción del suministro eléctrico y plagas. De modo que el equipo de seguridad, los encargados de mantenimiento y control de plagas o el equipo de montaje y manipulación de colecciones, si disponemos de él, nos aportarán información fundamental.

Por otro lado, debemos analizar exhaustivamente el espacio museístico para tener una percepción clara de los bienes presentes, su vulnerabilidad, la forma en que se exponen o almacenan y otras particularidades que puedan presentar [figura 3]. El objetivo es tener un conocimiento cualitativo y cuantitativo respecto al objeto de protección, esto es: saber qué tipo de colección o de bienes culturales se encuentran en cada espacio y su número, cuál es su forma de exposición o almacenamiento (obras de un misma colección, por ejemplo pintura, pueden exhibirse colgadas con cables a carril, con hembrillas y escarpias, pletinas, etc.), o si existen singularidades a tener en cuenta como pueden ser el peso, un sistema específico de apertura de vitrinas, elementos de seguridad con tornillería concreta, presencia de grandes formatos que condicionen el traslado por algunos de los recorridos de evacuación, etc. 

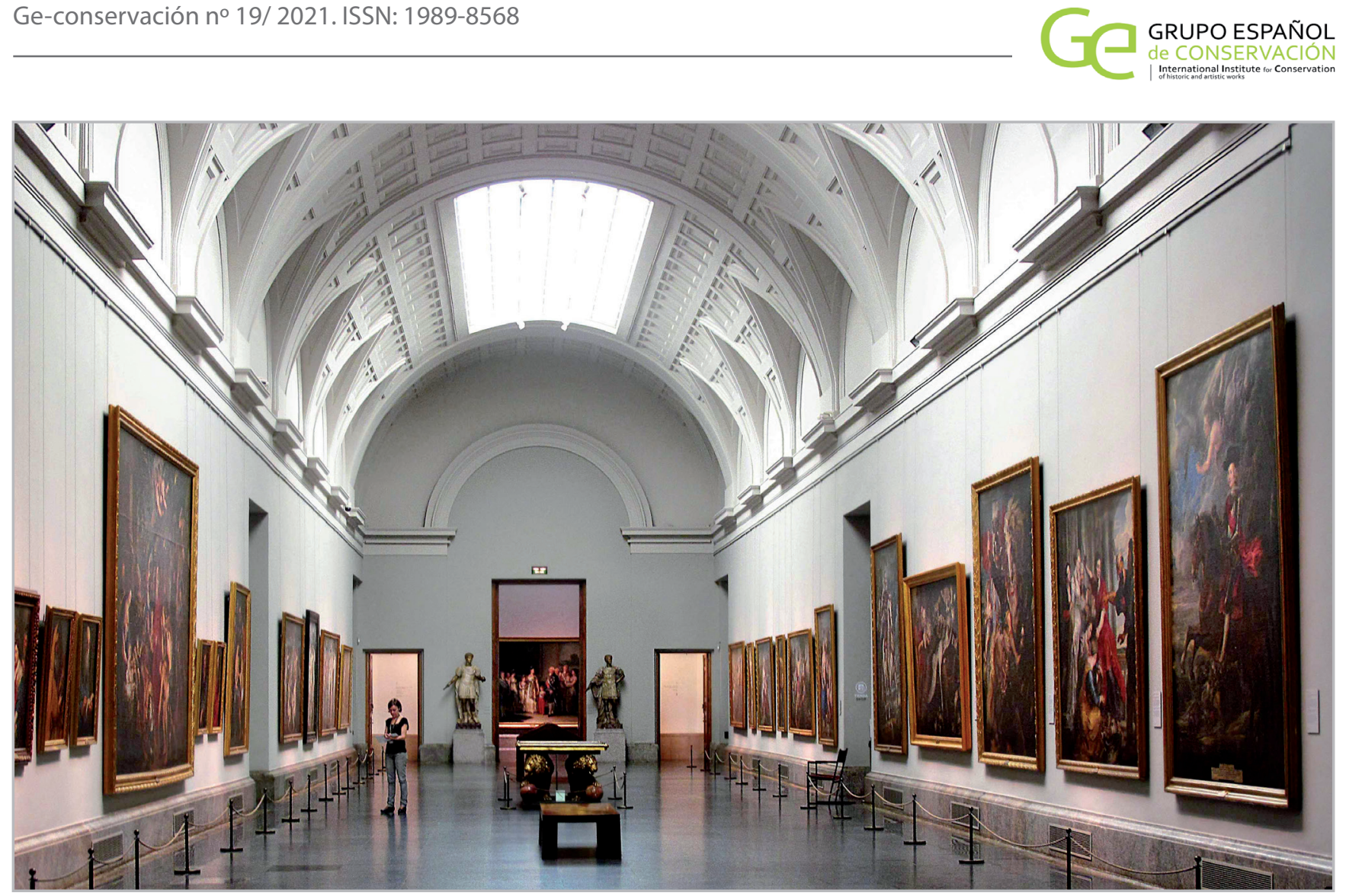

Figura 3.- Análisis del espacio de la galería central, Planta 1. Museo del Prado. Foto: Jaime García-Máiquez.
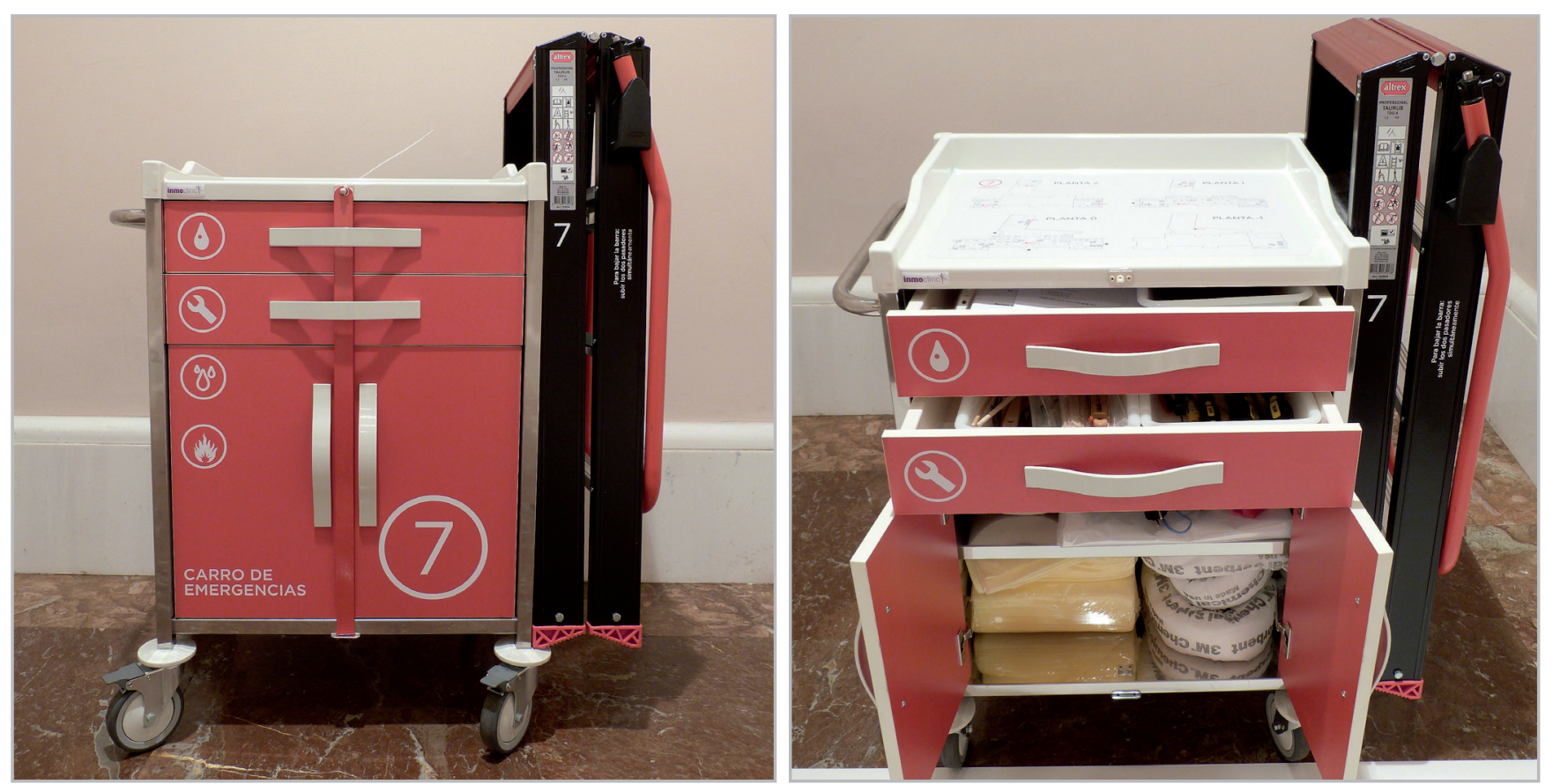

Figura 4 y 5.- Vista de carro de emergencias en Planta 2. Museo del Prado. Foto: Estrella Sanz.

Del mismo modo, hemos de recabar información sobre los recursos técnicos y materiales existentes necesarios para la evacuación interna o externa de obras o su protección in situ. [figuras 4 y 5 ]

Creemos que esta información es muy útil incorporarla en una ficha de identificación del espacio museístico estudiado, pero también en la ficha de análisis y evaluación de riesgo y en el plan de evacuación del mismo espacio, de tal forma que cada uno de los documentos, si los vemos o utilizamos de manera independiente, nos aporten toda la información completa de ese espacio. En la ficha de identificación del espacio museístico, también debemos reflejar sus características arquitectónicas: superficie que ocupa ese ámbito, su altura, medidas de accesos, características de cerramientos o cómo es la comunicación vertical con otras áreas. Finalmente, será preciso detallar los medios de protección frente a incendios e intrusión y aspectos en 
cuanto a medios organizativos como pueden ser protocolos específicos de acceso, limitaciones de aforo, etc.

Lo indispensable. Conocer el uso museístico de nuestras colecciones y sus particularidades, identificar la naturaleza de las amenazas, los medios disponibles para hacerlas frente, detectar carencias y proponer acciones que permitan mejorar la respuesta.

\section{Jerarquización de colecciones}

La clave. Una colección jerarquizada facilita enormemente la gestión porque nos ayuda a establecer prioridades en el destino de nuestros recursos económicos y humanos, no solo en lo que se refiere a actuaciones en situaciones de emergencia.

Lo ideal. Establecer equipos multidisciplinares que fijen criterios para la valoración de los bienes, ordenándolos en un listado jerarquizado.

Se deberán tener en cuenta si las obras son nuestras o se trata de depósitos temporales de otras instituciones. En este último caso, la responsabilidad del depositario es aún mayor, si cabe.

Para valorar un bien es fundamental contar con una buena documentación del mismo que nos permita determinar si se trata de un objeto que conserva su integridad original o ha sido gravemente alterado a lo largo del tiempo, si se encuentra en buen estado, si es raro o único, si es una obra maestra del arte universal, si pertenece a un conjunto, si conocemos la importancia de su creador, si ha sido especialmente apreciado por una comunidad concreta, etc. (REED 2018).

Es fundamental consensuar entre los participantes en el proceso de valoración la relación final de obras y las posiciones de cada una en la misma, reduciendo a una cifra manejable el número de piezas del listado: veinte obras pueden ser una buena cifra de partida. Si se realizan valoraciones por distintas personas, es esencial definir y compartir los mismos criterios, consensuando las posiciones relativas de cada bien en la lista.

No olvidar jamás que debemos establecer un marco de referencia para la valoración: un mismo bien puede tener un elevadísimo valor para una comunidad concreta y no tener ninguna relevancia en el contexto de la historia del arte universal.

Nada sería más triste que se perdieran obras de gran relevancia mientras se dedicaban esfuerzos al salvamento de bienes sin valor por puro desconocimiento de los miembros de los equipos de intervención o por la inexistencia de un listado jerarquizado.

Lo indispensable. Reflexionar sobre cuál sería la pieza clave de nuestra colección, al menos una, marcarla físicamente y destinar tiempo y recursos a garantizar su protección o su evacuación.

\section{Protección in situ}

La clave. Sin recursos para una evacuación masiva, no siempre deseable, la decisión de implantar sistemas de protección in situ nos lleva a buscar soluciones para las piezas más relevantes, especialmente si por su peso, fragilidad, ubicación o tamaño entrañan dificultad de traslado.

Lo ideal. Definir estratégicamente qué piezas serán protegidas y si el sistema o material utilizado tendrá que ser diseñado a medida. A veces, es conveniente comenzar por las obras de naturaleza más frágil, proponiendo la fabricación de vitrinas, marcos o contenedores de almacenamiento que proporcionen a los objetos protección permanente y que nos permitan desviar nuestros esfuerzos hacia la movilización de equipos para la instalación de fundas o para la evacuación simultánea de piezas que todavía no cuentan con sistemas de protección.

Decidir dónde se ubican los materiales de protección y qué aspecto tendrán sus contenedores, evitando siempre interferir con la experiencia de contemplación de los objetos. Para ganar tiempo de respuesta los recursos materiales deben localizarse lo más cerca posible de los bienes a proteger. Es muy útil emplear como alojamiento los propios soportes, vitrinas, marcos o mobiliario de almacenamiento $y$, si esto no fuera posible, debemos identificar los lugares, habitáculos o armarios más cercanos que nos permitan depositar nuestro equipamiento bien señalizado para ejecutar con fácil maniobra el procedimiento de protección.

Designar a los miembros de los equipos de intervención y entrenarles en los procedimientos operativos para el despliegue de las protecciones. Cuantas más personas compartan el conocimiento, más efectiva será la protección.

Buscar siempre las soluciones técnicas más simples, reduciendo al mínimo el tiempo de intervención.

En función de los riesgos presentes en cada espacio, tiene sentido invertir en materiales que respondan a cada necesidad. Por ejemplo, bajo un lucernario con carpintería metálica dañada que permite filtraciones en caso de precipitaciones extremas, conviene tener a mano y bien localizada una dotación de material impermeable. En función de la probabilidad de que el riesgo se convierta en daño, podemos decidir si el material será almacenado en forma de bobina continua o se confeccionarán fundas cortadas a medida para piezas concretas. En este último caso, cada funda debe ir marcada con el número de referencia del objeto correspondiente e, idealmente, 
identificada con la reproducción fotográfica del propio bien cultural.

La protección in situ debe plantearse de manera que jamás pueda generar riesgos hacia los objetos o hacia los miembros de los equipos de ejecución. Por eso es esencial probar una y otra vez las soluciones propuestas hasta decidir cuál será finalmente implantada. En la fase de desarrollo de soluciones técnicas se detectan y corrigen en detalle los pasos, materiales o recursos que pueden llegar a amenazar la integridad de los bienes [figuras 6 y 7]. En esta fase debemos descartar siempre que sea posible los trabajos en altura o que supongan maniobras "acrobáticas" dado que, en una emergencia real, las reacciones emocionales críticas alteran la capacidad de reacción.

Lo indispensable. Adquirir material mínimo para proteger las piezas del agua o del polvo si no tenemos recursos para la compra de carros de emergencia con suficiente dotación. Reflexionar sobre las necesidades de protección y evacuación de las piezas más importantes de la colección y definir soluciones técnicas, al menos, para la pieza que "todos salvarían" en caso de emergencia.

\section{Rutas de Evacuación}

La clave. Tener estudiados y establecidos los itinerarios de evacuación va a permitir disminuir los tiempos de respuesta y conocer con antelación posibles trabas. Además, evitaremos una improvisación que puede tener consecuencias fatales.

Lo ideal. Establecer una ruta de evacuación interna y una ruta de evacuación externa, definiendo en ambos casos una zona de triaje lo suficientemente alejada de la zona afectada y un destino para el almacenamiento temporal de los bienes culturales, tratando de que éste tenga unas condiciones ambientales similares a las habituales de las obras. Es esencial tener calculado previamente el volumen de espacio necesario para la reubicación temporal de los fondos evacuados y conocer la sobrecarga de uso de los forjados del espacio propuesto, debido a que acumulará de forma temporal un importante número de obras. No debemos olvidar señalar los recursos técnicos y materiales necesarios para la evacuación, en base a las características de los bienes presentes en la zona afectada. Dependiendo de las dimensiones de la institución es recomendable, si es posible, ubicar estas herramientas, llaves especiales, etc., necesarias para el acceso o desmontaje de las obras, en puntos o carros de emergencia distribuidos de forma estratégica -al menos uno por planta- con el objetivo de acelerar la actuación (Dorge y Jones 2004: 123), e indicar su ubicación.

Así mismo, y en el caso de ser posible, deberemos determinar alternativas para escenarios que, por ejemplo, limiten el uso de elementos de comunicación vertical
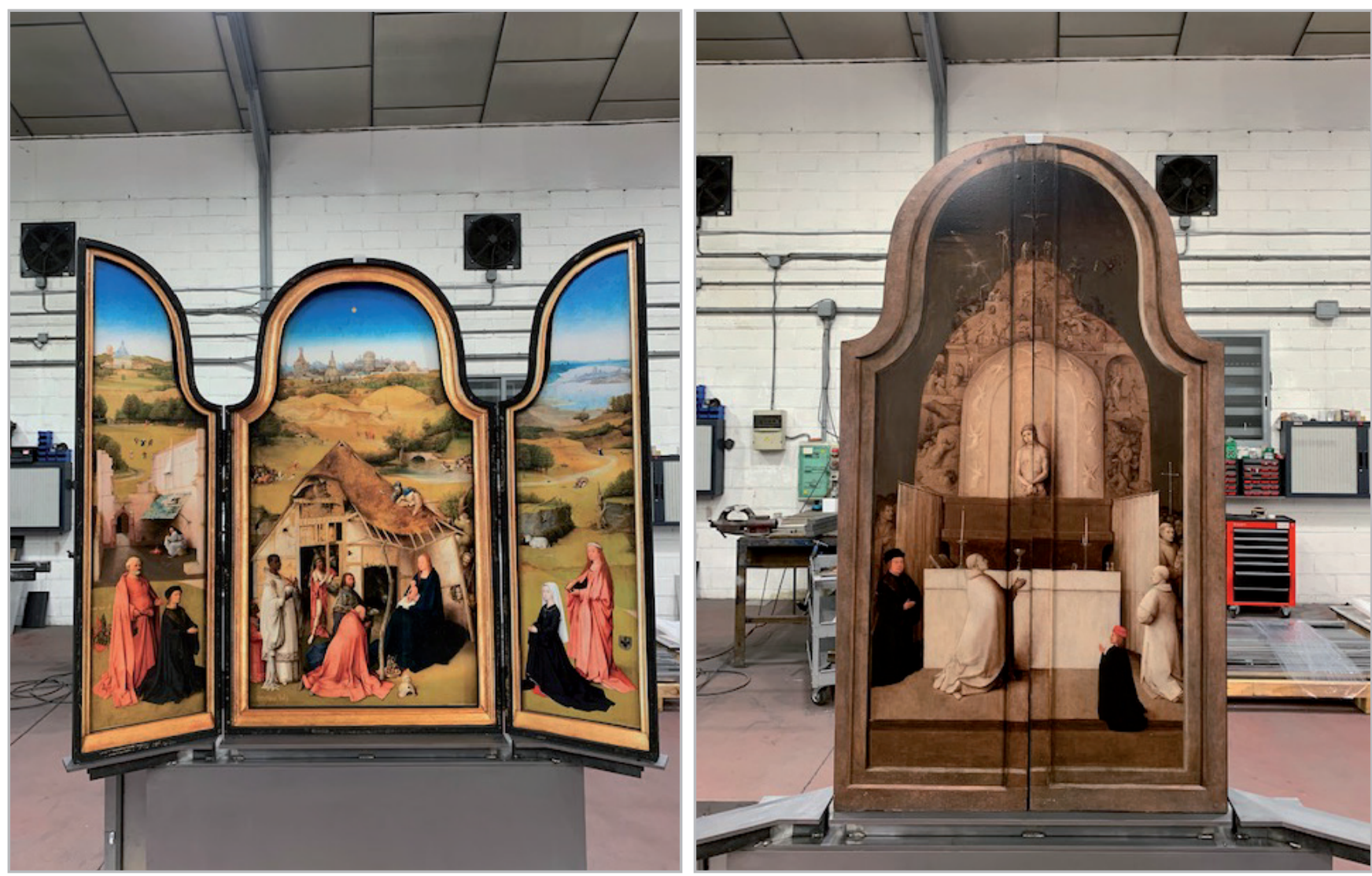

Figura 6 y 7.- Pruebas en taller con una reproducción exacta abierta y cerrada del Tríptico de la Adoración de los Reyes Magos del Bosco para la definición del sistema de protección. Foto: Marta Hernández. 
que pudieran ser necesarios (montacuadros) y que en un corte del suministro eléctrico o una emergencia por fuego quedarían anulados. Indicaremos en qué circunstancias se debe utilizar cada ruta en base a la amenaza.

Las rutas de evacuación también pueden estar condicionadas por los formatos de las obras, por esta razón deberemos tener identificadas estas particularidades en nuestro documento como hemos señalado anteriormente y especificar cómo se tiene que proceder para su movimiento y el itinerario alternativo a seguir.

Otra cuestión que puede surgir es la de valorar o proponer rutas de evacuación que, en el caso de una emergencia parcial, se puedan utilizar interfiriendo lo menos posible en la rutina de la institución. No obstante, debemos ser conscientes de que tanto la gravedad de la emergencia como las características arquitectónicas del edificio pueden condicionar o incluso imposibilitar esta opción.

Lo indispensable. Lo fundamental en este caso es priorizar, si es posible, la evacuación interna, ya que de este modo minimizaremos los riesgos de manipulación, de seguridad y limitaremos el uso de recursos externos. El nivel de emergencia y número de piezas afectadas será el factor determinante.

Por supuesto, debemos conocer previamente las limitaciones arquitectónicas que pueden obstaculizar una rápida evacuación. Las planimetrías y el análisis previo de espacios nos ayudan a ubicar estas zonas conflictivas y adelantar posibles soluciones.

Por último, mencionar el necesario control documental durante toda la evacuación y la indispensable designación previa de los espacios para almacenamiento temporal, tanto interno como externo por si el primero no fuera posible.

\section{Equipos internos de intervención}

La clave. Formar e informar a los miembros del equipo en las tareas asignadas y realizar simulacros de forma periódica va a contribuir a una mayor eficacia, minimizando riesgos para las personas y los bienes culturales (Dorge y Jones 2004: 89).

Loideal.El nivel de emergencia y la necesidad de evacuación interna o externa indudablemente va a definir la necesidad de medios y recursos humanos, determinando si son suficientes los propios o si tenemos que recurrir a recursos externos. En base a estos posibles escenarios deberemos tener establecidos nuestros equipos de intervención, pero para ello será fundamental tener claro nuestro organigrama interno y sus condicionantes (Culubret et al. 2008: 54).

Inicialmente deberíamos planificar el equipo asignando tareas acordes a la cualificación técnica del personal implicado en la respuesta y contando en él con un perfil técnico especializado en conservación/restauración de bienes culturales.

Es fundamental detectar posibles coincidencias entre Plan de Autoprotección y Plan de Protección de Colecciones al asignar las funciones de los miembros del equipo.

Según sus funciones y cometidos podríamos articular este equipo con una estructura similar a la detallada a continuación:

- Jefe de Emergencias: normalmente esta figura corresponde al Jefe de Seguridad de la institución o a la persona asignada en el Plan de Autoprotección. Ordena la evacuación tras la comunicación y consigna previa del Coordinador de Emergencias de Colecciones. Además, coordina a los equipos de seguridad que apoyan en la evacuación.

- Coordinador de Emergencias de Colecciones: esta figura debería corresponder a un técnico especializado en conservación y restauración. Entre sus funciones principales están evaluar la magnitud e impacto del siniestro, transmitir la orden de evacuación de colecciones al Jefe de Emergencias, y coordinar y establecer la secuencia de actuación del Equipo de Intervención. En consecuencia, debe conocer las rutas de evacuación, zonas de triaje y almacenamiento temporal para las obras evacuadas, así como las obras prioritarias de evacuación y/o protección in situ y las posibles particularidades que estas pudieran presentar.

- Responsable del puesto de mando: además de ejecutar las funciones establecidas en el Plan de Autoprotección, debe tener conocimiento del Plan de Protección de Colecciones ante Emergencias.

- El Equipo de Intervención y Evacuación: lo forma el personal que realiza las tareas de protección in situ o evacuación física de las obras y también el personal encargado de asegurar el control documental del movimiento si éste se llega a producir. Asimismo, este equipo debe conocer las obras prioritarias de evacuación o protección in situ, conocer la ubicación de medios auxiliares necesarios según el tipo de respuesta y estar habilitados o adiestrados para actuar en cada caso.

- Equipo de Apoyo: idealmente formado por personal de seguridad y mantenimiento, ayuda en tareas de control en el área de intervención o control de medios técnicos, puede dar asistencia al equipo de intervención si se les solicita o actuar como equipo de intervención en periodos de media o baja actividad en ausencia de otros colectivos.

Lo indispensable. Identificar y establecer las funciones y los mecanismos de actuación del equipo de intervención, teniendo en cuenta, en la planificación de respuesta, 
los periodos de actividad y la presencia horaria de los colectivos implicados. Elaborar un listado actualizado del personal implicado con sus datos de contacto, sin que jamás falte la figura del Coordinador de Emergencias de Colecciones.

\section{Coordinación con agentes externos}

La clave. Si la gravedad de la emergencia trasciende nuestra capacidad de respuesta, nos vemos obligados a recurrir a agentes externos.

Lo ideal. Contactar previamente con los posibles agentes externos implicados (Bomberos, Policía Nacional y Municipal, Protección Civil, Guardia Civil, Unidad Militar de Emergencias, etc.) para el conocimiento y familiarización con el edificio y sus bienes. De este modo se genera una actitud activa y se favorece la coordinación de una respuesta anticipada. Ésta última viene determinada por una buena distribución de los espacios externos y accesos al edificio, separando o secuenciando las necesidades de atención a personas y a bienes culturales. Son previsiones vitales la señalización en el pavimento de las zonas que carecen de suficiente capacidad de carga para el estacionamiento de los vehículos de emergencias pesados o tener perfectamente identificados los ascensores que tienen garantizado el suministro eléctrico durante cualquier siniestro.

Según la magnitud de la emergencia y el alcance territorial de la misma, entrarán en servicio los distintos planes a nivel local, autonómico y nacional. En caso de grave afectación de bienes de interés cultural especialmente singulares, es conveniente que los comités asesores y los centros de coordinación de la emergencia cuenten con un criterio técnico específico para atender las necesidades de salvaguarda del patrimonio. Si se categoriza la emergencia como de interés nacional, debería intervenir el propio Ministro de Cultura y Deporte.

Contar con el DPI (documento para la intervención de Bomberos), en el que se recoge, de modo extremadamente esquemático, los riesgos presentes en el inmueble y los datos más relevantes con vistas a la intervención en siniestro. Incluye datos sobre el tipo de estructura del edificio, los focos de peligro y los sistemas de protección frente a incendios (bocas de incendio equipadas, hidrantes, alumbrado de emergencia, etc.). Permite introducir una mención a la existencia de un Plan para Colecciones en el campo de observaciones.

La manipulación de los bienes culturales en caso de protección in situ o de evacuación entraña a veces riesgos tan elevados para las piezas que debemos reflexionar sobre la conveniencia y alcance de la intervención de agentes externos, lo que convierte en crucial la formación y capacitación del personal. Las circunstancias de cada emergencia exigirán respuestas distintas.
Establecer contactos previos con empresas de servicios, que puedan colaborar en el embalaje y transporte de bienes a lugar seguro, garantiza su rapidez de movilización en caso de emergencia.

Por último, es esencial buscar vías de colaboración con otras instituciones próximas para el apoyo mutuo en caso de siniestro y para cubrir la necesidad de compartir espacios para almacenamiento provisional de bienes culturales y materiales o personal técnico que pueda ser movilizado en caso de intervención de gran calado.

Lo indispensable. La preceptiva visita técnica de Bomberos a nuestras instalaciones para orientar a los responsables de Seguridad y Mantenimiento, detectando cuestiones críticas y formulando propuestas para facilitar la intervención corrigiendo defectos no identificados previamente.

\section{Evaluación del siniestro}

La clave. En la evaluación del siniestro tratamos de reflejar, con una visión global, la transcendencia del suceso acontecido, recogiendo múltiples aspectos que permitan hacer una valoración para adoptar la actuación más acorde a la circunstancia (Dorge y Jones 2004: 160). Puede haber una evaluación inicial y/o una evaluación final.

Lo ideal. Lo deseable, pero no siempre posible al estar condicionado por el nivel de emergencia e incluso por el horario en el que se produce el suceso, es poder hacer, si se dispone de tiempo, una evaluación inicial del siniestro que permita ajustar al máximo el plan de respuesta y la toma de decisiones. El Coordinador de Emergencia de Colecciones debería ser el encargado de llevar a cabo o coordinar esta evaluación inicial para poder priorizar las actuaciones y la secuencia de tareas. Por ejemplo, valorando la conveniencia de dar prioridad a la protección in situ de aquellos bienes que presenten una dificultad para su evacuación y/o, además, dispongan de fundas diseñadas para esta posibilidad; o, por el contrario, decidiendo la necesidad de una evacuación interna o externa, debido al riesgo o volumen de obras afectadas o en riesgo de serlo.

Con este objetivo de utilidad inmediata, aunque también de fuente referencial a posteriori, y de concepción como visión panorámica del suceso, debemos idear un formulario o una ficha estructurada que contemple los múltiples aspectos implicados en el siniestro o, al menos, los que se indican a continuación:

- Fecha del siniestro: si tiene que ser una evaluación a posteriori o no inmediata por alguna de las circunstancias antes apuntadas, señalaremos la fecha del siniestro y también la fecha en la que se realiza la evaluación.

- Responsable de la evaluación: en este caso puede ser interesante indicar, además del autor, la persona que 
descubre el siniestro o incidencia y que contribuye o puede contribuir con información sobre el suceso. Puede ser una fuente a la que sea necesario recurrir más adelante.

- Localización y zona afectada: nos referimos al espacio o espacios del edificio, elementos arquitectónicos dentro de éste y elementos museográficos que se han visto implicados.

- Tipo de siniestro: relacionados con los posibles riesgos previamente establecidos (daño antropogénico -terrorismo, robo, vandalismo-, fuerzas físicas, fuego, agua, interrupción de suministro eléctrico o plagas).

- Bienes culturales afectados: cuántos, de qué tipología y severidad del daño cuantificando, además, las piezas según la gravedad del daño.

- Necesidades de actuación como pueden ser medidas de protección in situ, indicando para qué obras o, en su caso, conveniencia de traslados.

- Inventario de los bienes culturales afectados indicando su origen, destino y grado de afectación.

- Áreas implicadas en la actuación.

Lo indispensable. Si la urgencia de la actuación no ha permitido realizar o completar una evaluación inicial, debemos hacer o retomar la evaluación del siniestro una vez que la amenaza esté controlada o estabilizada, ya que esta evaluación va a ser el documento de partida que ayude a elaborar el plan de recuperación y facilite el diseño de un programa de actuaciones y los recursos necesarios para su consecución.

\section{Conclusión}

El Plan de Protección de Colecciones ante Emergencias del Museo del Prado nace adaptándose a las circunstancias, recursos y necesidades de la institución. Esto ha permitido, mediante el examen, identificación, análisis y evaluación de los medios de protección técnicos y humanos existentes, la creación de una estrategia operativa para neutralizar los riesgos identificados y minimizar los posibles daños en la colección ante una situación de emergencia.

Conscientes de las particularidades de cada institución que alberga y custodia bienes culturales y de que las circunstancias del Museo del Prado pueden ser excepcionales en algunos casos, entre otros en cuanto a dotación de personal de seguridad, mantenimiento, conservación y restauración, etc., o medios y recursos técnicos, se ha optado no tanto por relatar de forma exhaustiva el procedimiento o contenidos específicos del plan de protección de colecciones del museo, sino por destacar aquellos elementos que consideramos imprescindibles en el diseño de cualquier plan similar y buscar, dentro cada uno de ellos, aspectos que bajo nuestra experiencia hemos considerado decisivos (claves), aquellos que serían deseables o que al menos deberíamos tener en nuestra perspectiva de trabajo (lo ideal) y por último, los que en ningún caso deberíamos obviar (lo indispensable).

En definitiva, la variedad de circunstancias y las múltiples cuestiones expuestas, ponen de manifiesto la necesidad de un trabajo multidisciplinar y cooperativo donde confluyen conocimientos y fuentes de información diversas. Igualmente, no debemos olvidar que el éxito de nuestro plan sólo será posible con el consenso, compromiso e implicación de todo el personal que trabaja en la institución.

\section{Referencias}

CULUBRET, E. et al. (2008). Guía para un Plan de Protección de Colecciones ante Emergencias. Madrid: Ministerio de Cultura.

DORGE, V. y JONES, S. (2004). Creación de un Plan de Emergencia. Guía para museos y otras instituciones culturales. Los Ángeles: The Getty Conservation Institute.

REED, CAROLINE. (2018). Reviewing Significance 3.0. https:// collectionstrust.org.uk/resource/reviewing-significance-3-0/. [consulta: 23/01/2021].

UNDRR. United Nations Office for Disaster Risk Reduction. (2015). ¿Qué es el Marco de Sendai para la Reducción de Riesgos de Desastres?. https://www.undrr.org/es/implementando-el-marcode-sendai/que-es-el-marco-de-sendai-para-la-reduccion-delriesgo-de. [consulta: 23/01/2021].

\section{Autor/es}

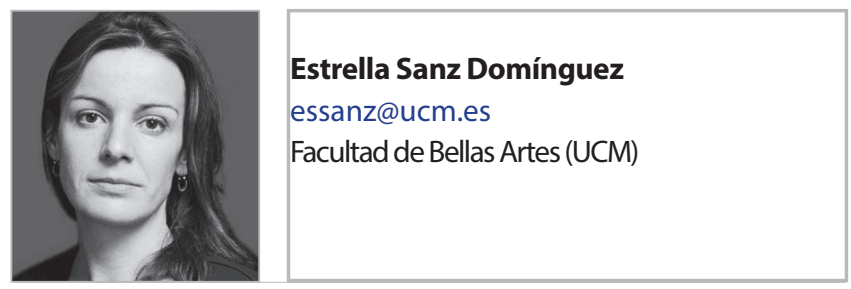

Conservadora Restauradora de Bienes Culturales por la Universidad Complutense de Madrid (1996), Magíster en Conservación Preventiva de Obras de Arte y Bienes Culturales, UCM (2006) y Doctora en Bellas Artes por la UCM (2015), en el programa de Conservación y Restauración de Patrimonio Cultural. En el ámbito de la formación investigadora ha obtenido diversas becas de conservación y restauración en el Instituto de Patrimonio Cultural de España (IPCE, 2004-2006), y de Museología en el Museo Nacional del Prado (2012). Profesionalmente, ha trabajado en materia de conservación-restauración para diferentes instituciones públicas: Museo del Ejército, IPCE, Museo Naval, Museo Nacional de Artes Decorativas, Museo del Traje o Ministerio de Cultura y Deporte, con una asistencia técnica para la definición de la conservación 
y sistemas expositivos del nuevo Museo del Ejército en el Alcázar de Toledo. Asimismo, ha realizado varios proyectos como técnico especialista en Conservación Preventiva y Protección de Colecciones ante Emergencias para el Museo Nacional del Prado y para el Ministerio de Asuntos Exteriores, Unión Europea y Cooperación, dentro de su Área de Bienes Culturales. Además, ha colaborado con empresas privadas en diferentes proyectos de conservación y restauración por todo el territorio nacional. Actualmente es docente en el Grado de Conservación y Restauración de Patrimonio Cultural y en el Máster de Conservación del Patrimonio Cultural de la Facultad de Bellas Artes (UCM).

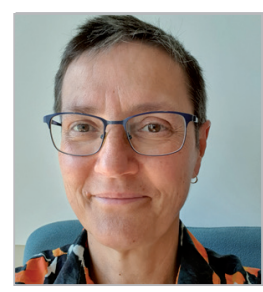

\section{Marta Hernández Azcutia}

marta.hernandez@museodelprado.es Jefa de Servicio de Colección Permanente Museo Nacional del Prado

Marta Hernández Azcutia, miembro del Cuerpo Facultativo Superior de Conservadores de Museos desde 1998, se licenció en Antropología Americana por la Universidad Complutense de Madrid y trabajó inicialmente como arqueóloga en distintos yacimientos españoles y franceses. Posteriormente, obtuvo la titulación oficial en conservación y restauración de bienes arqueológicos por la ESCRBC de Madrid. La instalación del Laboratorio de Restauración y la implantación de la política de conservación preventiva en el Museo Nacional de Ciencia y Tecnología fueron hitos en su primer trabajo museístico de envergadura. Disfrutó de una breve estancia en el Ministerio de Cultura centrada en la planificación y ejecución de proyectos museísticos y, como funcionaria de carrera, ocupó la Jefatura del Departamento de Conservación Preventiva del Museo del Ejército de Madrid, planificando, coordinando y dirigiendo entre los años 1999 y 2003 las primeras fases del traslado de las colecciones al Alcázar de Toledo. En la actualidad, trabaja como Jefa del Servicio de Colección Permanente del Museo Nacional del Prado llevando el control de la conservación preventiva y la presentación museográfica de los bienes culturales expuestos. En su último trabajo de trascendencia, ha definido los aspectos técnicos que han regido la contratación del nuevo montaje del Tesoro del Delfín y ha formado parte del equipo de seguimiento del proyecto. Es responsable técnica del nuevo montaje del Bosco en el que se han aplicado principios de sostenibilidad, accesibilidad y conservación preventiva concebidos con un enfoque global. Entre otras tareas, coordina la redacción e implantación del Plan de Protección de Colecciones ante Emergencias en su museo. 